\title{
La problemática tributaria de los contratos de asociación en participación $\left({ }^{*}\right)(* *)$
}

\section{The tax problems of the Partnership agreement (Joint Venture)}

\author{
Octavio Salazar Mesías(***) \\ PwC Perú
}

\begin{abstract}
Resumen: En el presente artículo el autor realiza un análisis del régimen impositivo vinculado al contrato de asociación en participación, en el marco de un reciente pronunciamiento de la máxima autoridad administrativa en materia tributaria. Al respecto, el autor nos presenta un interesante recuento de los cambios normativos acontecidos alrededor del contrato de asociación en participación; y nos presenta una postura interesante con relación a los efectos que la Resolución del Tribunal Fiscal tendría de cara a los contribuyentes. Finalmente, dando énfasis al escenario de incertidumbre en torno a la figura descrita, el autor insta a la creación de normas apropiadas que otorgue seguridad jurídica a los actores en el mercado.
\end{abstract}

Palabras clave: Asociación en participación - Tribunal Fiscal - Impuesto a la Renta - Seguridad Jurídica.

\begin{abstract}
In this article, the author analyzes the tax regime linked to the partnership agreement (joint venture) agreement, within the framework of a recent court resolution by the administrative authority on tax matters. In this regard, the author presents an interesting summary of the normative changes that took place around the partnership agreement, and presents us with an interesting position concerning the effects that the Tax Court Resolution would have on taxpayers. Finally, emphasizing the scenario of uncertainty surrounding the figure described, the author urges the creation of appropriate standards that provide legal security to the actors in the market.
\end{abstract}

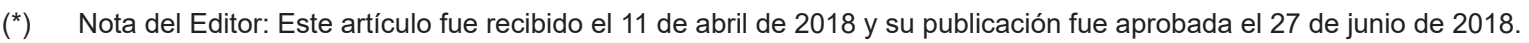

${ }^{* *}$ Artículo presentado en el marco del proceso de admisión 2018 del Instituto Peruano de Derecho Tributario (IPDT), para acreditar la versación en materia tributaria.

${ }^{* * *}$ Abogado por la Pontificia Universidad Católica del Perú. Adjunto de docencia del curso "Derecho Tributario" de la Facultad de Ciencias Contables en la misma casa de estudios. Estudios de Especialización en Derecho Tributario Internacional por la Universidad Austral de Buenos Aires, Argentina. Abogado Junior de PwC Perú. Correo electrónico: octavio.salazar@ pe.pwc.com 
La problemática tributaria de los contratos de asociación en participación The tax problems of the Partnership agreement (Joint Venture)

Key words: Partnership agreement (Joint Venture) - Tax Court Income Tax - Legal security.

Sumario: 1. Introducción_2. Naturaleza jurídica del CAEP_3. Tratamiento tributario del CAEP_3.1.Impuesto a la Renta_3.2. Impuesto General a las Ventas_3.3 Distribución al asociado en el ámbito de un Convenio para Evitar la Doble Imposición_4. 4. De la Resolución N 637-2-2017 y el asociante como único contribuyente del IR_5. Reflexiones finales_6. Referencias bibliográficas.

\section{Introducción}

El objeto del presente artículo es compartir brevemente algunas reflexiones sobre el tratamiento tributario aplicable al contrato de asociación en participación (en adelante, "CAEP") en el Perú; con especial énfasis en la atribución de los resultados del negocio que realiza el asociante en favor del asociado para efecto del Impuesto a la Renta (en adelante, "IR").

Para ello, revisaremos ciertas cuestiones críticas en torno a la naturaleza jurídica del CAEP, así como en cuanto a las relaciones entre las partes contratantes desde el ámbito fiscal. En particular, nos detendremos en la impresión que nos ha dejado la reciente Resolución del Tribunal Fiscal $N^{\circ}$ $637-2-2017^{(1)}$.

\section{Naturaleza jurídica del CAEP}

Como se sabe, el CAEP es un contrato asociativo y no un contrato de sociedad, no obstante, está regulado en el artículo 440 de la Ley General de Sociedades ${ }^{(2)}$ (en adelante, "LGS") que lo define como aquél por el cual una persona, denominada asociante, le concede a otra u otras personas, denominadas asociados, una participación en el resultado o en las utilidades de uno o varios negocios o empresas (del asociante); a cambio de determinada contribución.

Así, dentro de las características de este tipo de contrato, tenemos que: (i) el asociante actúa en nombre propio; (ii) la gestión del negocio corresponde al asociante; (iii) no existe relación jurídica entre los asociados y terceros; (iv) respecto de los terceros, los bienes contribuidos por el asociado se presumen de propiedad del asociante, salvo los que se encuentren inscritos en Registros Públicos a nombre del asociado; y, (v) las partes deciden si la participación en las pérdidas es en la misma proporción que en las utilidades, o si se participa en las utilidades pero no en las pérdidas, o si se participa en las utilidades o en las pérdidas aunque el asociado no haya efectuada una contribución.

En palabras de Talledo Mazú, una nota distintiva del CAEP es "la participación del asociado en los resultados o utilidades del asociante a cambio de una contribución. Mas esa nota es insuficiente por sí solo para la debida caracterización del contrato. A tal fin, debe ser complementada con las demás que fluyen de la regulación legal del contrato como sigue: actuación del asociante en nombre propio, (...) gestión y rendición de cuentas a cargo exclusivo del asociante, (...) inexistencia de vínculo jurídico entre el asociado y terceros (...)"(Talledo 1998).

En este orden de ideas, la característica esencial de un CAEP sería la existencia de un negocio cuyo titular y gestor es el asociante, quien se obliga a ceder parte del resultado de dicho negocio a favor de un tercero, el asociado, a cambio de una contribución. Nótese que las enumeradas características del CAEP derivan estrictamente de su regulación societaria.

Ahora bien, con relación a la naturaleza jurídica de las relaciones entre las partes contratantes del CAEP, García-Pita y Lastres señala que, en los contratos de asociación en participación regulados en la LGS, las estructuras de las relaciones jurídicas son bilaterales y directas, a diferencia de lo que ocurre en las sociedades

(1) De fecha 23 de enero de 2017.

(2) Ley No 26887. 
Octavio Salazar Mesías

en donde "las relaciones son plurilaterales y radiales" (GarcíaPita 2008). Agrega el autor que, "no hay, propiamente [en las sociedades], una relación sinalagmática directa entre los socios, ni las aportaciones que se efectúen en consideración de supuestas contra-aportaciones, sino que se trata de aportar bienes o servicios para el ejercicio en común de actividades económicas" (García-Pita 2008, 56).

Véase que, si bien la postura antes descrita es aceptada por un sector mayoritario de la doctrina y por la autoridad tributaria, la posición de la Corte Superior de Justicia de Lima es distinta.

En efecto, cabe tener en consideración que, en la sentencia recaída en el Expediente $N^{\circ} 1461-2002$ (del 15 de diciembre de 2002), la Sala Civil de Lima precisó que "el CAEP no es un contrato de prestaciones recíprocas, toda vez que el asociante no está en la obligación de efectuar una prestación a favor del asociado y viceversa, de modo que el contrato subsiste simplemente en la participación del asociado en el riesgo del negocio, siempre y cuando éste efectúe una contribución para el desarrollo del mismo (Hundskopf 2005)".

\section{Tratamiento tributario del CAEP}

\subsection{Impuesto a la Renta(3)}

Debemos iniciar este punto indicando que, de acuerdo con el texto de la Ley del IR, aprobada por Decreto Legislativo $N^{\circ} 774^{(4)}$, hasta el año 1998 para efectos del IR los ingresos de los CAEP se regulaban bajo el régimen de "atribución de rentas" entre las partes contratantes. Así, el artículo 14 del citado Decreto precisaba lo siguiente:

"Artículo 14.- Son contribuyentes del impuesto:

(...) En caso de sociedades de hecho, asociaciones en participación, joint ventures, consorcios, comunidad de bienes y demás contratos de colaboración empresarial, las rentas serán atribuidas a las personas naturales o jurídicas que las integran o sean parte contratante".
Asimismo, el artículo 65 de la citada norma señalaba que "las sociedades de hecho, asociaciones en participación, joint ventures, consorcios, comunidad de bienes y demás contratos de colaboración empresarial, perceptores de rentas de tercera categoría, deberán llevar contabilidad independiente de la de sus socios o partes contratantes (el énfasis es del autor)".

Sobre lo anterior, Indira Navarro sostuvo que "los resultados del contrato debían ser atribuidos a las partes integrantes, incorporándolos a sus respectivos y propios resultados. En tal sentido, los ingresos mensuales se consideraban atribuidos a las partes contratantes en la misma proporción en la que hubieran acordado participar en el contrato sobre las rentas anuales" (Navarro 2002, 93).

Como se advierte, si bien los CAEP se regían por el régimen de atribución de rentas descrito en el párrafo anterior, existían otros contratos identificados en el Registro Único de Contribuyentes (en adelante, "RUC"); siendo que estos tenían una contabilidad independiente a la de sus partes y asumían la calidad de contribuyentes del IR.

Ahora bien, con la publicación de la Ley $N^{\circ} 27034$ en diciembre de 1998 y vigente desde enero de $1999^{(5)}$, se modificaron las citadas disposiciones, eliminándose toda referencia expresa a que los contratos de asociación en participación debían llevar contabilidad independiente del artículo 65 de la Ley del IR.

(3) Cuyo T.U.O, fue aprobado por el Decreto Supremo $N^{\circ} 179-2004-E F$.

(4) Publicado el 31 de diciembre de 1993 en el Diario Oficial "EI Peruano". Cuyo T.U.O. fue aprobado por Decreto Supremo N 179-2004-EF.

(5) En atención al artículo 2 de la Ley $N^{\circ} 27063$, se precisa que la vigencia de la Ley $N^{\circ} 27034$ es a partir del 1 de enero de 1999. 
La problemática tributaria de los contratos de asociación en participación The tax problems of the Partnership agreement (Joint Venture)

En adición a ello, se modificó el último párrafo del artículo 14 de la Ley del IR, y se estableció que sólo se considerarán como contribuyentes de dicho impuesto a los contratos de colaboración empresarial que Ileven contabilidad independiente, eliminándose toda referencia a los CAEP:

“(...) en el caso de las sociedades irregulares previstas en el artículo 423 de la Ley General de Sociedades, excepto aquéllas que adquieren tal condición por incurrir en las causales previstas en los numerales 5 y 6 de dicho artículo; comunidad de bienes, joint ventures, consorcios y demás contratos de colaboración empresarial que no lleven contabilidad independiente, las rentas serán atribuidas a las personas naturales o jurídicas que las integran o que sean parte contratante".

Es precisamente dicha modificación la que introdujo el inciso k) del artículo 14 de la Ley del IR, estableciéndose que para efectos del impuesto se consideran personas jurídicas a "las sociedades irregulares previstas en el artículo 423 de la Ley General de Sociedades; la comunidad de bienes; joint ventures, consorcios y otros contratos de colaboración empresarial que lleven contabilidad independiente de la de sus socios o partes contratantes".

En efecto, este sería para muchos el origen de un gran problema, puesto que habiéndose eliminado de la Ley del IR toda referencia al tratamiento tributario de los CAEP, no fueron pocos quienes entendieron ello como el fin del régimen de transparencia para tal tipo de contratos.

Es de resaltar que, en el proyecto normativo de la glosada Ley $\mathrm{N}^{\circ} 27034$ se mencionó que: “(...) carece de sustento jurídico atribuir rentas al asociado u obligar a la asociación en participación a llevar contabilidad independiente. Esta medida permitirá, además, dar un tratamiento similar al dispensado en las normas del IGV cuyo reglamento señala que la asociación en participación no es sujeto de dicho impuesto, excluyéndola del concepto contratos asociativos".

En este contexto, el profesor Humberto Medrano, advirtiendo prontamente la problemática derivada de la (des)regulación de Ios CAEP, indicó lo siguiente: "como quiera que ahora no se les menciona, resulta claro que no deben llevar contabilidad independiente ni son contribuyentes, pero falta establecer si el único sujeto del tributo es el asociante o si la renta generada debe atribuirse a los asociados (el énfasis es del autor)" (Medrano 2000, 102).

Con posterioridad a lo acontecido, el 31 de diciembre de 1999 se publicó el Decreto Supremo $N^{\circ}$ 194-99-EF(6), que modificó el Reglamento de la Ley del IR; y, cuya Séptima Disposición Final indicó que lo regulado a través de la Ley $N^{\circ} 27034$ en torno a los CAEP resultaba aplicable para el ejercicio gravable de 1999, y para aquellos CAEP existentes a la fecha de entrada en vigencia de dicha norma:

"Precisase que lo establecido en la Ley $\mathrm{N}^{\circ}$ 27034, es aplicable en el ejercicio gravable de 1999, incluso para aquellos contratos de colaboración empresarial y asociaciones en participación existentes a la fecha de entrada en vigencia de dicha norma (...)".

De igual manera, se indicó que en los CAEP en donde se hayan atribuido ingresos a los partícipes para efecto de los pagos a cuenta, debía presentarse declaraciones rectificatorias, siendo ello aplicable también a los casos en donde se hubiera llevado contabilidad independiente y atribuido ingresos en el ejercicio 1999:

“(...) En consecuencia, en aquellos casos en que los contratos de colaboración empresarial durante 1999 hubieran atribuido sus ingresos a las personas naturales o jurídicas que las integren o sean partes contratantes para efecto de los pagos a cuenta del impuesto, se deberá presentar las declaraciones rectificatorias y el pago respectivo hasta el vencimiento del plazo para la presentación de la Declaración Jurada Anual del ejercicio 1999. Para este efecto, será de aplicación

(6) Publicado el 31 de diciembre de 1999 en el Diario Oficial "El Peruano". 
Octavio Salazar Mesías

lo dispuesto en el numeral 1 del artículo 170 del Código Tributario.

Tratándose de las asociaciones en participación que hubieran llevado contabilidad independiente de la de sus partes contratantes y atribuido los correspondientes ingresos, durante el referido ejercicio, será aplicable a dichas partes lo dispuesto en el párrafo anterior en lo que se refiere a la presentación de las declaraciones rectificatorias y el numeral 1 del artículo 170 del Código Tributario.

La SUNAT dictará las normas complementarias para la aplicación de lo dispuesto en la presente Disposición (el énfasis es del autor)".

Ciertamente, la citada norma se encargó de regular la situación de los CAEP que durante 1999 hubieran Ilevado contabilidad independiente a la de sus partes contratantes. De igual modo, el Decreto dispuso que la Administración Tributaria dictaría las normas complementarias para la aplicación de sus disposiciones, considerando la falta de precisión de las disposiciones vigentes en dicho período.

Con ello, se podría argumentar que "la SUNAT habría quedado facultada para emitir las reglas relativas al tratamiento de los CAEP en el ejercicio 1999; y, consecuentemente, no avalar el establecimiento de reglas definitivas basándose en tal autorización (Medrano 2000, 105)".

Finalmente, el 21 de marzo de 2000, mediante la Resolución de Superintendencia $\mathrm{N}^{\circ}$ 42-2000/SUNAT, la Administración reguló lo concerniente a los CAEP que durante 1999 hubieran llevado contabilidad independiente a la de sus partes contratantes e inscrito en el RUC.

Al respecto, la citada Resolución en su artículo 6 señaló lo siguiente:

"Artículo 6.- Tratamiento de la participación

El asociado declarará la participación como renta neta de tercera categoría del IR y el Asociante la deducirá como gasto o costo, según corresponda".

Es oportuno detenernos en este punto con especial cuidado, toda vez que pese a los antecedentes normativos que motivaron la publicación de la aludida disposición y a la carencia de indicadores por parte de la Ley del IR y su Reglamento, se consideró válido aplicar el citado artículo sexto a todos los CAEP en general, inclusive a los celebrados con posterioridad a 1999.

- Tratamiento para el asociante

Conforme lo hemos expuesto, ni la Ley del IR ni su Reglamento contemplan el tratamiento del CAEP, siendo la única referencia normativa vigente la comentada Resolución de Superintendencia. De este modo, ante la duda generada por la falta de reglas precisas, la doctrina nacional y la práctica empresarial se encargaron de proponer sus propias soluciones con relación al régimen aplicable a los CAEP, entre las cuales resaltaron dos posiciones:

"Posición 1: Sostener que el asociante debía registrar en su contabilidad los ingresos totales por las ventas, así como deducir los gastos en que incurriera el negocio, procediendo luego a hacer entrega a la asociada de la participación que le correspondería, deduciéndola también como gasto. La referida entrega constituiría renta de tercera categoría para la asociada, por lo cual, tributarían por su cuenta cada una de las partes.

Posición 2: Sostener que el asociante debía registrar en su contabilidad los ingresos totales por las ventas, así como deducir los gastos en que incurriera el negocio, procediendo luego a liquidar y determinar el IR a pagar. Lógicamente, la participación de la asociada sería entregada luego de deducido el IR, por lo cual, se le estaría haciendo entrega de renta desgravada" (el énfasis es del autor). (Castillo 2012, 60)

Cabe señalar que, una tercera posición también fue discutida en su oportunidad 
La problemática tributaria de los contratos de asociación en participación The tax problems of the Partnership agreement (Joint Venture)

entre los administrados, en virtud de la cual el resultado atribuido al asociado podría calificar como un dividendo, toda vez que "la retribución percibida resulta similar al del socio de una sociedad, pues en ambos casos hay un derecho abstracto a la utilidad que puede generar la empresa y una obligación, que también es abstracta, de asumir las pérdidas hasta el valor del aporte o contribución" (Castillo 2012, 68).

Así, como finalmente sucedió en los hechos, en general se aceptó la primera posición, considerándose que el asociante fuese quien debía registrar todas las operaciones vinculadas al CAEP; siendo aquel quien tributara por las rentas que se deriven de la ejecución del negocio, deduciendo como gasto la participación del asociado, quien a su vez debe considerarla también como renta gravada.

Sobre lo anterior, Jorge Picón señaló que “(...) el artículo 6 de la Resolución de Superintendencia $N^{\circ}$ 42-2000/SUNAT toma una posición indicando tácitamente que, el resultado sobre el que se participa se calcula antes de impuestos, siendo por lo tanto deducible para el Asociante el pago que realiza el Asociado (el énfasis es del autor)".

Ahora bien, la deducción de gastos para fines tributarios se rige por el principio de causalidad establecido en el artículo 37 de la Ley del IR, conforme al cual son deducibles los gastos necesarios para generar renta gravada o mantener su fuente productora, en tanto no se encuentren prohibidos o limitados por la ley.

No obstante que del texto del citado artículo podría interpretarse que solo son admisibles como gastos, aquellos directamente vinculados a la generación de renta gravada o al mantenimiento de la fuente, el Tribunal Fiscal ha interpretado en sentido amplio el antedicho principio de causalidad.

En efecto, en reiterada jurisprudencia, tales como la $\mathrm{N}^{\circ} 814-$ 2-1998 y N ${ }^{\circ} 710-2-1999$, el Tribunal Fiscal ha señalado que:

"El principio de causalidad es la relación de necesidad que debe establecerse entre los gastos y la generación de renta o el mantenimiento de la fuente, noción que en nuestra legislación es de carácter amplio, pues se permite la sustracción de erogaciones que no guardan dicha relación de manera directa. No obstante ello, el principio de causalidad debe ser atendido, por lo cual para ser determinado deberán aplicarse criterios adicionales como que los gastos sean normales al giro del negocio o éstos mantengan cierta proporción con el volumen de las operaciones, entre otros (el énfasis es del autor)".

En tal escenario, la necesidad de un gasto dependería de las circunstancias y características de cada negocio, satisfaciendo el requisito de causalidad aquellos gastos que resulten normales para la actividad comercial de la empresa. En cuanto al CAEP, se entendió que la participación en el resultado del negocio que corresponde al asociado, constituye, por su propia condición, un gasto deducible para el asociante.

En línea con lo expuesto, la participación atribuida por el asociante al asociado sería consecuencia del cumplimiento de una obligación cuyo origen está propiamente en el CAEP. Por tanto, en aplicación del principio de causalidad recogido en el artículo 37 de la Ley del IR, puede entenderse que la erogación efectuada por el asociante como consecuencia de la atribución de la participación al asociado (en caso se hayan generado utilidades), califica como un gasto necesario para mantener la fuente generadora de renta.

Es de notar que, este tratamiento se sustentó fundamentalmente en la Resolución de Superintendencia $\mathrm{N}^{\circ} 42-2000 / S U N A T$ y en las actuaciones que la Administración Tributaria realizaba en procedimientos de fiscalización; siendo que la posición inclusive habría sida avalada por el Tribunal Fiscal.

De ello, se tiene que en la Resolución $N^{\circ} 7527-$ 3-2010 el referido órgano señaló lo siguiente:

"Que asimismo este Tribunal en la Resolución N 732-5-2002 ha establecido que corresponde al asociante registrar 
Octavio Salazar Mesías

en su contabilidad los ingresos totales por las ventas y todos los gastos incurridos, de acuerdo con lo establecido por el precitado inciso k) del artículo 14 de la Ley del IR, deduciendo como gasto las participaciones que entrega a sus asociados.

Que, en el caso de autos, la Administración no discute la naturaleza económica del contrato de asociación en participación celebrado con las citadas empresas, ni el carácter de deducible como gasto para la determinación del IR de la participación en el resultado del negocio (atribución de la utilidad), siendo que en el presente reparo solo corresponde analizar si el gasto deducido se encuentra debidamente sustentado (el énfasis es del autor)".

En este orden de ideas, la primera posición que indicáramos con anterioridad tomó terreno en el mercado, volviéndose aquel tratamiento de los CAEP el elegido por la mayoría de inversionistas en la estructuración de sus operaciones.

- Tratamiento para el asociado

Al respecto, la Ley del IR en su artículo 1 establece que dicho impuesto grava:

“a) Las rentas que provengan del capital, del trabajo y de la aplicación conjunta de ambos factores, entendiéndose como tales aquellas que provengan de una fuente durable y susceptible de generar ingresos periódicos.

b) Las ganancias de capital

c) Otros ingresos que provengan de terceros, establecidos por la Ley.

d) Las rentas imputadas, incluyendo las de goce o disfrute, establecidas por la Ley."

A su vez, el último párrafo del artículo 3 de la norma antes citada señala que, en general, constituye renta gravada de las empresas, cualquier ganancia o ingreso derivado de operaciones con terceros, así como el resultado por exposición a la inflación determinado conforme a la legislación vigente.

Por su parte, el inciso g) del artículo 1 del Reglamento de la Ley del IR establece que la ganancia o ingreso derivado de operaciones con terceros a que alude el último párrafo del artículo 3 de la Ley del IR, se refiere a la obtenida en el devenir de la actividad de la empresa en sus relaciones con otros particulares, en las que los intervinientes participan en igualdad de condiciones y consienten el nacimiento de obligaciones.

Como fluye de las normas glosadas, el IR considera como rentas gravadas, entre otras, a las que responden al criterio de renta-producto y a las ganancias consideradas dentro del criterio de flujo de riqueza. En tal sentido, la atribución de utilidades que obtenga el asociado por su participación, tratándose de una persona jurídica, resultará afecta al IR.

Dicha renta además constituiría un resultado gravable de la tercera categoría, tal como se prevé en el inciso e) del artículo 28 de la Ley:

\section{"Artículo 28.- Son rentas de tercera categoría}

Las demás rentas que obtengan las personas jurídicas a que se refiere el Artículo 14 de esta ley y las empresas domiciliadas en el país, comprendidas en los incisos a) y b) de este artículo o en su último párrafo, cualquiera sea la categoría a la que debiera atribuirse"(7)

En este orden de ideas, si producto de la ejecución del negocio a cargo del asociante,

(7) En efecto, a través de la Resolución N 6994-9-2010, el Tribunal Fiscal indicó que “(...) Las rentas que generen las empresas domiciliadas califican en todos los casos como rentas de tercera categoría, independientemente de la categoría a la que debieran atribuirse". 
La problemática tributaria de los contratos de asociación en participación The tax problems of the Partnership agreement (Joint Venture)

se generase un resultado positivo y surgiese el derecho de cobro en favor del asociado; el ingreso que se le atribuya constituirá renta gravada. La cual además debiera ser calificada como de tercera categoría al provenir de una fuente empresarial.

\subsection{Impuesto General a las Ventas ${ }^{(8)}$}

En cuanto a este punto, si bien el pronunciamiento del Tribunal Fiscal centra su análisis en el CAEP dentro del ámbito del $\mathrm{IR}$, estimamos conveniente brindar un sucinto repaso de la dinámica de dicha figura en el marco del Impuesto General a las Ventas (en adelante, "IGV").

Así, de acuerdo a lo establecido por la Ley del IGV en su artículo 1 , se encuentra gravada con dicho impuesto la venta en el país de bienes muebles; así como la prestación o utilización de servicios en el país.

Para tales efectos, según lo dispuesto en los incisos a) y b) del artículo 3 de la norma citada, se entiende por venta a todo acto por el que se transfieren bienes a título oneroso, independientemente de la designación que se dé a los contratos o negociaciones que originen esa transferencia y de las condiciones pactadas por las partes, así como al retiro de bienes con excepción de los señalados en la Ley y su Reglamento ${ }^{(9)}$.

Con relación a bienes muebles, se entiende a aquellos corporales que pueden llevarse de un lugar a otro, los derechos referentes a los mismos, los signos distintivos, invenciones, derecho de autor, derechos de llave y similares, las naves y aeronaves, así como los documentos y títulos cuya transferencia implique la de cualquiera de los mencionados bienes.

De igual modo, conforme a lo previsto en el numeral 1 del inciso c) del artículo 3 del mencionado dispositivo, debe entenderse como servicio, entre otros, a toda prestación que una persona realiza para otra y por la cual percibe una retribución o ingreso que se considere renta de tercera categoría para los efectos del IR, aun cuando no esté afecto a este último impuesto; incluidos el arrendamiento de bienes muebles e inmuebles y el arrendamiento financiero.
Por otro lado, los contribuyentes del impuesto tienen el derecho a utilizar como crédito fiscal, el tributo pagado en las adquisiciones de bienes, servicios y contratos de construcción destinados a la realización de operaciones gravadas con el mismo.

Ahora bien, en lo que concierne al CAEP y el IGV, debiera distinguirse entre dos situaciones: (i) el aporte efectuado por el asociado; $y$, (ii) la atribución de resultados por su participación.

Respecto del aporte efectuado por el asociado, aquel podría integrarse por distintos conceptos (importes de dinero, bienes muebles o bienes inmuebles). En cuanto a ello, es de indicar que el Reglamento de la Ley del IGV, en su artículo 2, precisa que no se consideran bienes muebles, entre otros, las acciones, participaciones en sociedades de hecho, contratos de colaboración empresarial, asociaciones en participación y similares.

Bajo este tenor, toda vez que los conceptos que integran el aporte efectuado por el asociado responderían a la finalidad de participar en el desarrollo de determinado proyecto, y, en consecuencia, en los beneficios que genere su explotación; dicho aporte no se encontrará gravado con el IGV.

De otro lado, con relación a la participación del asociado, aquella no se encuentra gravada con el impuesto, toda vez que no califica como la retribución por un servicio. A tal efecto, atendiendo a la naturaleza de los CAEP, hemos señalado que se entiende que los asociados no le prestan un servicio al asociante, sino que realizan un aporte a un negocio específico con el objeto de obtener participación en el mismo y las ganancias que se generen por su ejecución. Por tanto,

(8) Cuyo T.U.O. fue aprobado por D.S. N $055-99-E F$.

(9) Aprobado por D.S. N029-94-EF. 
Octavio Salazar Mesías

la participación que el asociante le entregue al asociado no se encontrará gravada con el IGV.

Sin embargo, de acuerdo con distintos pronunciamientos del Tribunal Fiscal, debe tenerse presente que ello ocurrirá siempre que estemos ante un CAEP, constituyendo un elemento determinante para calificar un contrato como tal que el asociado tenga participación en las utilidades del negocio; y, por tanto, asuma el riesgo del mismo conjuntamente con el asociante.

En efecto, a través del a Resolución N 958-3-2003, se indicó lo siguiente:

"Que, en el caso de autos, se observa que mediante el contrato suscrito entre la recurrente y Esarci S.R.L., se acordó que esta última iba a implementar y conducir un casino en el Hotel de la recurrente, negocio respecto del cual existe un interés común, que consiste en prestar el servicio de casino en las instalaciones del Hotel; asimismo, ambas partes participan en el negocio, puesto que si bien Esarci S.R.L. es la encargada de conducir el negocio, la recurrente también tiene participación, lo cual se advierte tanto de las prestaciones a su cargo, como de la participación en las utilidades.

Que, en ese sentido, atendiendo a que los ingresos reparados obedecen a la participación de la recurrente en un contrato asociativo, esta instancia deberá levantar tales reparos al IGV (el énfasis es del autor)".

Como fluye del citado criterio, si el asociado sólo participa del negocio en función a los ingresos obtenidos, el Tribunal Fiscal sería de la postura que, al no existir participación en el riesgo, se trata de un servicio gravado con el IGV.

En adición a lo anterior, es importante resaltar el pronunciamiento del Tribunal provisto en la Resolución $\mathrm{N}^{\circ}$ 120-1-2000:

"Que el referido pago del 13\% fue acordado en función a las ventas y no a las utilidades que pudiera obtener CEFOISA, atenuando de esta forma el riesgo inherente al desarrollo de un negocio conjunto, que es precisamente una de las principales características de la asociación en participación, según se desprende de la definición prevista en el artículo $N^{\circ} 398$ de la Ley General de Sociedades vigente a la fecha de celebración del mencionado contrato (el énfasis es del autor)".

En dicho caso, en la medida que el CAEP suscrito por el contribuyente no perseguía los objetivos comerciales de dichos contratos, el referido órgano resolvió que "(...) La cesión de la unidad económica efectuada por la recurrente califica como una prestación de servicios en el país, por lo que se encuentra afecta al IGV".

De lo expuesto, tenemos que, si la participación del asociado en un CAEP se determina en función a los ingresos o a las ventas del negocio, la retribución que se le distribuya será considerada como una contraprestación por un servicio, la misma que se encontrará gravada con el IGV. Por el contrario, si se participa en las utilidades del negocio, la retribución que perciba será el resultado de un negocio y no estaría gravada con el impuesto.

\subsection{Distribución al asociado en el ámbito de un Convenio para Evitar la Doble Imposición}

Si bien no es propósito del presente trabajo agotar el análisis en cuanto a este punto, mención aparte merecen los acuerdos y/o convenios (bilaterales o multilaterales), denominados convenios para evitar la doble imposición (en adelante, "CDIs"). En efecto, se trata de instrumentos internacionales a través de los cuales los Estados firmantes renuncian a su jurisdicción tributaria sobre determinadas ganancias, actividades o patrimonios y acuerdan que sólo uno de dichos Estados tenga derechos de cobro sobre el impuesto; o, en todo caso, que se realice una imposición compartida ${ }^{(10)}$. Los mencionados acuerdos

(10) Daniel Echaiz Moreno, “Los Convenios para Evitar la Doble Tributación”, Revista Derecho \& Sociedad 33 (2009): 137-47. En similar sentido, Renée Villagra refiere que: 


\section{La problemática tributaria de los contratos de asociación en participación The tax problems of the Partnership agreement (Joint Venture)}

se basan en el Modelo elaborado por la Organización para la Cooperación y el Desarrollo Económico (OCDE)(11), al que denominaremos "MOCDE" (Blanco 2013, 5).

Al respecto, el Perú mantiene siete (7) CDIs plenamente vigentes en nuestro ordenamiento. Nos referimos a aquellos celebrados con Brasil, Canadá, Chile, Corea, México, Portugal y Suiza; y, si bien no ahondaremos en el estudio de aquellos CDIs, es importante traerlos a colación para el tema que nos avoca.

Así, por ejemplo, tenemos que en todos los CDls suscritos y vigentes por Perú, se refiere que los beneficios de una empresa de un Estado Contratante solamente pueden someterse a imposición en ese Estado, a no ser que la empresa realice su actividad en el otro Estado por medio de un establecimiento permanente situado en él, en cuyo caso los beneficios de la empresa pueden someterse a imposición en el otro Estado, pero solo en la medida que puedan atribuirse a ese establecimiento permanente.

En esta línea, podemos tomar como ejemplo el CDI entre Perú y Chile ${ }^{(12)}$, en donde todos los beneficios empresariales percibidos por una empresa chilena y pagados por una empresa peruana, sólo serán gravables en Chile, en la medida que dichos beneficios no sean atribuibles a un establecimiento permanente de la empresa chilena en el Perú.
Ahora bien, de nuestra revisión de los CDIs, observamos que el común de ellos no brinda una definición del término beneficios empresariales; por ello, es pertinente citar la disposición del artículo 3 de aquellos ("Definiciones Generales"), en donde se establece lo siguiente:

"Para la aplicación del Convenio por un Estado Contratante en un momento dado, cualquier expresión no definida en el mismo tendrá, a menos que de su contexto se infiera una interpretación diferente, el significado que en ese momento le atribuya la legislación de ese Estado relativa a los impuestos que son objeto del Convenio, prevaleciendo el significado atribuido por la legislación impositiva sobre el que resultaría de otras ramas del Derecho de ese Estado".

En este aspecto, cabe indicar que, en los Comentarios al MOCDE, se menciona:

"(...) Aun cuando no se ha considerado necesario definir el término 'beneficios' en el convenio, debe entenderse en todo

"Los Convenios para evitar la doble imposición constituyen un instrumento internacional por el cual los Estados firmantes (obligados) acuerdan:

- Renunciar a su jurisdicción tributaria sobre determinadas ganancias y deciden que sea sólo uno de los Estados el que cobre el impuesto; o,

- Realizar una imposición compartida, es decir, que sean ambos Estados los que graven na través del uso de tasas complementarias, otorgando por lo general, el derecho primigenio al gravamen al país de la fuente hasta un porcentaje determinado".

Véase en: Renée Villagra Caymana, "Los convenios para evitar la doble imposición y prevenir la evasión fiscal (con énfasis en los convenios vigentes en el Perú)", en: CDls - Convenios para evitar la Doble Imposición (IFA - Perú, 2008), $22-23$.

(11) Organismo al que también se alude como "OECD", por sus siglas en inglés: Organization for the Economic Cooperation and Development.

(12) "Artículo 7.- Beneficios empresariales

1. Los beneficios de una empresa de un Estado Contratante solamente pueden someterse a imposición en ese Estado, a no ser que la empresa realice su actividad en el otro Estado Contratante por medio de un establecimiento permanente situado en él. Si la empresa realiza o ha realizado su actividad de dicha manera, los beneficios de la empresa pueden someterse a imposición en el otro Estado, pero sólo en la medida en que puedan atribuirse a ese establecimiento permanente. (...)".

(13) De fecha 7 de febrero de 2007. 
Octavio Salazar Mesías

caso que el término, utilizado en este artículo y en los restantes del convenio, tiene un significado amplio que incluye todas las rentas procedentes de la explotación de una empresa. Esta significación amplia se corresponde con la significación otorgada al término en la legislación fiscal de la mayoría de los países de la OCDE (el énfasis es del autor)".

Dicha definición también habría sido adoptada por parte de la Administración Tributaria. En efecto, a través del Informe $N^{\circ}$ 30-2007-SUNAT/2B0000(13), con relación al CDI Perú - Canadá, la SUNAT se remitió expresamente a la citada disposición de los Comentarios para definir el término beneficio empresarial.

Ahora bien, entendemos que las rentas de bienes inmuebles; actividades de transporte terrestre, marítimo, aéreo; dividendos; intereses; o, regalías, no se consideran beneficios empresariales, en tanto aquellas mantienen reglas especiales en los CDIs.

Con relación a los dividendos, por ejemplo, la definición contenida en los CDIs no incluye expresamente a las participaciones obtenidas por el asociado en el ámbito de un CAEP. Al respecto, es de notar que en los Comentarios al artículo 10 del $\mathrm{MOCDE}^{(14)}$ se establece lo siguiente:

"Artículo 10.- Dividendos

(...) 3. El término 'dividendos', en el sentido de este artículo, significa las rentas de las acciones, de las acciones o bonos de disfrute, de las participaciones mineras, de las partes de fundador u otros derechos, excepto los de crédito, que permitan participar en los beneficios, así como las rentas de otras participaciones sociales sujetas al mismo régimen fiscal que las rentas de otras participaciones sociales sujetas al mismo régimen fiscal que las rentas de acciones por la legislación del Estado de residencia de la sociedad que hace la distribución."
Como puede advertirse, la definición de dividendos provista en el Párrafo 24 de los Comentarios al MOCDE se vincularía con "las distribuciones de utilidades a que dan derecho las acciones", haciendo clara alusión a una sociedad de capitales. Asimismo, agrega el texto que "las ventajas a que da derecho una participación social no se atribuyen por regla general, más que a los propios accionistas".

De acuerdo a ello, no resultaría posible asimilar a priori los beneficios obtenidos por el asociado a la definición de dividendos establecida en los CDIs, puesto que aquella hace referencia a los rendimientos pagados a los accionistas y no a las utilidades generadas por participar en el desarrollo de un negocio mediante la suscripción de un contrato.

Lo expuesto encuentra mayor sustento en el caso especial del CDI entre Perú y Portugal, cuyo Protocolo en su artículo 4 precisa que, para efectos de dicho CDI, el término dividendo incluye también las rentas atribuidas por una asociación en participación(15).

Por otro lado, tampoco podría considerarse que la distribución en favor del asociado responda al concepto de intereses, de acuerdo con la definición contenida en los CDIs. En efecto, los Comentarios al artículo 11 precisan que el término interés se refiere a las rentas de créditos de cualquier naturaleza. De este modo, se menciona que la "expresión 'créditos de cualquier naturaleza' engloba a los depósitos en efectivo y los valores en numerario, así como los títulos públicos, y los bonos y obligaciones, aunque estos tres últimos se mencionen especialmente por

(14) Disposición que se repite en las ediciones del MOCDE concerniente a los años 2003, 2008, 2010,2014 y 2017.

(15) Al respecto, el Protocolo del CDI entre Perú y Portugal en su artículo 4 refiere:

“(...) 4. Con referencia al Artículo 10, párrafo 3

En el caso de Portugal, el término "dividendo" deberá incluir también las rentas atribuidas por un acuerdo de asociación en participación ("associacao em partipacao")". 
La problemática tributaria de los contratos de asociación en participación The tax problems of the Partnership agreement (Joint Venture)

razón de su importancia y de ciertas particularidades que pueden comportar".

En consecuencia, siendo el interés todo tipo de rendimiento producto del otorgamiento de un crédito, no puede considerarse que la retribución percibida por el asociado se encuentre dentro de dicha definición, puesto que dicha retribución del aporte realizado podría derivar en una ganancia o una pérdida. Asimismo, para aquellos CDIs cuyas disposiciones hacen remisión expresa a la legislación del país de la fuente sobre la definición de dividendos y/o intereses, nuestra legislación local no califica a las utilidades percibidas por el asociado como un dividendo o un interés.

Por tanto, tratándose de ingresos obtenidos por el asociado como consecuencia de su participación en el negocio, en nuestra opinión debiera calificarse a dicha renta como un beneficio empresarial, rigiéndose por las disposiciones del artículo 7 de los CDIs ${ }^{(16)}$. De este modo, los resultados obtenidos en Perú por una entidad residente de un Estado Contratante (salvo para el caso puntual de Portugal), se encontrarán gravadas únicamente en dicho Estado, a menos que la empresa realice su actividad empresarial por medio de un establecimiento permanente situado en el país.

Una vez más, no pretendemos extendernos en la incidencia de los CAEP cuando media un CDI; sin embargo, es preciso puntualizar lo concerniente a la configuración de un establecimiento permanente por parte del participante en un CAEP. En efecto, en el artículo 5 de los convenios que Perú mantiene vigentes se indica que, la expresión establecimiento permanente significa un lugar fijo de negocios, mediante el cual una empresa realiza todo o parte de su actividad.

Bajo tal escenario, a fin de determinar si el asociado (como sujeto no domiciliado), a través del asociante, realiza actividad empresarial en un lugar fijo de negocios en nuestro país; será necesario analizar el caso concreto. Así, de darse dicho supuesto, los beneficios serían atribuidos al establecimiento permanente; por ende, Perú también tendrá potestad para gravar dicha renta.

\section{De la Resolución $\mathbf{N}^{\circ} 637$ - 2-2017 y el asociante como único contribuyente del IR}

Habiendo identificado los antecedentes del CAEP en el ámbito tributario y las principales posiciones que se generaron en torno a su tratamiento, es necesario reiterar que actualmente ni la Ley del IR ni su Reglamento han desarrollado expresamente el régimen que debiera aplicarse a esta figura. Sin embargo, conforme lo hemos advertido, en la práctica tomó lugar la perspectiva en donde el asociante fuese quien registrará todas las operaciones vinculadas al CAEP, tributando por las rentas propias del negocio y deduciendo como gasto la participación del asociado, quien a su vez debe considerarla también como renta gravada.

Cabe resaltar que, dicha postura fue sustentada fundamentalmente en la Resolución de Superintendencia $N^{\circ}$ 42-2000/SUNAT.

Sin perjuicio de lo anterior, existió una corriente jurisprudencial discordante de la posición expuesta, conforme a la cual el asociante sería el titular del negocio y, por tanto, el único encargado de su conducción; y, en aquel recaería la obligación de tributar por el íntegro de la renta producto de los resultados. Mientras que la participación que reciba el asociado calificaría como un ingreso no afecto al IR; o, sencillamente, como renta desgravada.

Es precisamente en ese contexto donde se emite la Resolución N 637-2-2017, de fecha 23 de enero de 2017, mediante la cual el Tribunal Fiscal ha concluido lo siguiente:

"Que tomando en consideración las previsiones normativas de la Ley del IR aplicables para el ejercicio materia de análisis y que el asociante

(16) Es importante advertir la presencia de una corriente distinta, conforme a la cual se considerarían los resultados atribuibles al asociado (sujeto no domiciliado) en el marco de un CAEP, dentro del ámbito del artículo 21 de los CDIs ("Otras Rentas"). 
Octavio Salazar Mesías

es el titular exclusivo del negocio o empresa objeto del contrato, mientras que el asociado se limita a entregar una contribución a cambio del derecho a participar en los resultados, se concluye que en el presente caso, de obtenerse utilidades en el negocio o empresa materia del contrato, el asociante será el único obligado a determinar y pagar el IR de Tercera Categoría por la totalidad de las rentas gravadas que se obtuvieran de dicho negocio o empresa y, luego de ello, de corresponder, deberá entregar la participación que corresponda al asociado, quien no debe gravar nuevamente la suma recibida con el IR, por lo que corresponde revocar la apelada en este extremo (el énfasis es del autor)".

Si bien la citada Resolución se pronuncia puntualmente sobre la situación del asociado, se indica que el asociante tendría que pagar el tributo por el íntegro de la utilidad generada del negocio, incluyendo la porción de la renta que según el contrato le corresponda al asociado. A su vez, este último no estaría obligado a tributar por la utilidad que se distribuya a su favor, puesto que, de acuerdo con la posición del Tribunal, el asociante "deberá entregar la participación que corresponda al asociado, quien no debe gravar nuevamente la suma recibida con el IR (el énfasis es del autor)".

En la misma línea, no correspondería que el asociante aplique ninguna retención sobre el importe distribuido al asociado. Véase que, bajo esta lógica, las partes del contrato deberían convenir que la utilidad del asociado se calcularía sobre el importe que resulte después que el asociante pague el impuesto sobre el íntegro de la renta.

Es de advertir que, en el caso concreto, es el propio Tribunal Fiscal quien sostiene que no corresponde reconocer como renta gravada la participación del asociado; apartándose del criterio adoptado por la SUNAT.

En efecto, en el supuesto en cuestión, para la Administración Tributaria el tratamiento que resultaba aplicable al contribuyente (como asociado) encontraba sustento en el artículo 6 de la Resolución de Superintendencia N42-2000/SUNAT. Mientras que, para el Tribunal, dicha norma sólo configuraba un régimen transitorio aplicable al ejercicio 1999:

"Que carece de sustento lo señalado por la Administración en el sentido que de la revisión de la cláusula segunda del contrato de asociación en participación celebrado entre la recurrente y la empresa (...) y la Resolución de Superintendencia $\mathrm{N}^{\circ}$ 42-2000/SUNAT, el monto de la participación correspondiente al asociado constituye renta de tercera categoría para él, según lo dispuesto en el artículo 6 de la referida norma, por cuanto esta creó un régimen transitorio aplicable al ejercicio 1999 para los contratos de asociación en participación existentes al 1 de enero de 1999 que hubieran llevado contabilidad independiente a la de sus partes contratantes y atribuido a éstas, durante dicho año, las rentas correspondientes a la asociación en participación".

En el marco descrito, el órgano resolutor concluye que, de obtenerse utilidades en el negocio o empresa materia del contrato, el asociante será el único obligado a determinar y pagar el IR por la totalidad de las rentas gravadas obtenidas y, luego de ello, entregar la participación que corresponda al asociado; revocando la apelada en este extremo.

Como puede verse, aun cuando no estamos frente a un pronunciamiento de observancia obligatoria, el argumento compartido por la Sala 2 del Tribunal irrumpe una línea argumentativa que venía siendo aplicada con frecuencia, tanto por la Administración Tributaria como por los contribuyentes.

Igualmente, debemos mencionar que este no es el primer pronunciamiento del Tribunal Fiscal en donde se comparte este enfoque. En efecto, si bien con la Resolución N 637 2-2017 se ha desarrollado con mayor claridad el argumento que sostiene la posición en referencia, previamente el citado órgano ya había hecho mención -sutilmente y sin ampliar en detalles- a la "renta desgravada" que el asociado recibiría del $\mathrm{CAEP}^{(17)}$.

(17) Véase las Resoluciones del Tribunal Fiscal N 18351-4-2013 y N 5366-4-2014. 
La problemática tributaria de los contratos de asociación en participación The tax problems of the Partnership agreement (Joint Venture)

\section{Reflexiones finales}

Desde nuestra perspectiva, la Resolución en comentario nos deja más dudas que certezas. Ciertamente, hay temas que deberán ser atendidos y revisados a profundidad para efecto de mantener la coherencia con la línea argumentativa que adopta ahora mismo el Tribunal Fiscal. En principio, pensamos en los siguientes tópicos:

a) ¿Qué pasará en lo siguiente con aquellas fiscalizaciones de la SUNAT y procedimientos tributarios en curso, respecto del tratamiento de los CAEP?

Entendemos que, en caso la Administración opte por seguir la postura que adopta el Tribunal Fiscal, y cuestionar el tratamiento de los CAEP, cabría para los contribuyentes la aplicación del artículo 170 del Código Tributario, respecto de la improcedencia de la aplicación de intereses, del índice de precios al consumidor y de sanciones en casos de duplicidad de criterio.

b) Si en el marco de la Resolución el asociante tributa por el $100 \%$ de las utilidades del negocio, ¿qué sucederá en los casos donde el asociante tuviese utilidad en dicho negocio, pero pérdida en sus actividades comerciales en general? Desde la perspectiva del asociado, entendemos que éste de la misma manera mantendría intacto su derecho a recibir utilidades en función a su participación en el negocio o empresa; por tanto, el asociante quedaría asimismo obligado a concederle las utilidades generadas y que correspondan. En el caso concreto, si bien el asociante no tendría la obligación de pagar el IR debido a las pérdidas generadas, entendemos que dicha salvedad solo aplicaría para la utilidad del negocio que le sea propiamente atribuido. En cambio, tratándose de la participación del asociado, dicho importe le sería distribuido considerando el impuesto correspondiente. Ahora bien, al no considerar aplicable la Resolución de Superintendencia $\mathrm{N}^{\circ}$ 42-2000/SUNAT, no existe regulación respecto de cómo es que el asociante podría asumir el pago del IR que gatille la utilidad del asociado a propósito de su distribución.

c) Sobre lo anterior, ¿qué pasaría con la compensación de pérdidas por parte del asociante en el marco del artículo 50 de la Ley del IR (quien tendría utilidad en un negocio de CAEP y pérdida por su actividad empresarial general) ?; y, ¿por parte del asociado?
Recordemos que, en atención a nuestro ordenamiento tributario, luego de determinar el resultado contable de la empresa en el ejercicio, $y$ aplicar las deducciones y adiciones en función a las normas tributarias se obtendrá un resultado tributario. A tal efecto, dicho resultado puede ser de utilidad o pérdida tributaria. Precisamente, el artículo 50 de la Ley del IR y el artículo 29 de su Reglamento regulan los sistemas de compensación de pérdidas y rentas empresariales.

Teniendo en cuenta ello, bajo la lógica del Tribunal Fiscal, el asociante tendría que asumir como propia toda la pérdida del negocio, sin importar la presencia del asociado.

En este orden de ideas, cabría preguntarnos si este último podría considerar como pérdida el monto total de su aporte.

d) Si el importe atribuido por parte del asociante al asociado estaría desgravado ¿cuál sería la naturaleza jurídica de aquél? Es ésta una importante cuestión que no ha sido abordada por la Resolución en comentario.

e) De igual manera, ¿cuál sería el tratamiento para los sujetos no domiciliados que se constituyan como asociados en un CAEP que genere utilidades?; $y$, ¿qué ocurre con los CDIs?

Siendo que el IR siempre aplicaría en cabeza de los asociantes (como sujetos domiciliados), se estaría asegurando un gravamen integral por los resultados del negocio. Por lo mismo, la participación del asociado no domiciliado no estaría sujeta a imposición en nuestro país.

Lo expuesto no significa que, en el país de domicilio del asociado, no puedan gravarse los resultados atribuidos.

De la misma manera, en el supuesto de que medie un CDI y se generen beneficios empresariales para el asociado residente de un Estado Contratante, entendemos que el importe atribuido igualmente podría someterse a imposición en el país del asociado. 
Octavio Salazar Mesías

f) Por otra parte, ¿qué sucedería con los pagos a cuenta del IR de las partes del CAEP?

Con relación a este punto, en el marco de la posición sostenida en la aplicación general de la Resolución de Superintendencia $N^{\circ} 42-2000 / S U N A T$ para el tratamiento de los CAEP, el asociante debía incluir la totalidad de los ingresos del negocio para efecto de sus pagos a cuenta; mientras que el asociado, quien no se encontraba obligado a computar dicho importe, regularizaba un importante impuesto al final del ejercicio debido a la atribución.

Es de recordar que, de acuerdo con el artículo 85 de la Ley del IR, los contribuyentes que obtengan rentas de tercera categoría abonarán con carácter de pago a cuenta del impuesto que en definitiva les corresponda pagar por el ejercicio gravable, dentro de los plazos previstos por el Código Tributario, cuotas mensuales que determinarán con arreglo a alguno de los sistemas establecidos en la norma; en los cuales se toma como parámetro base los ingresos netos del contribuyente.

Al respecto, para propósito de lo dispuesto en dicho artículo, se consideran ingresos netos al total de ingresos gravables de la tercera categoría, devengados en cada mes, menos las devoluciones, bonificaciones, descuentos y demás conceptos de naturaleza similar que respondan a la costumbre de la plaza; e impuesto calculado, al importe determinado aplicando la tasa a que se refiere el primer párrafo del artículo 55 de la Ley.

Bajo este panorama, estando obligado el asociante a pagar el IR por la renta total producto de la ejecución del negocio, debería calcular los pagos a cuenta del mes incluyendo el íntegro de los ingresos generados.

En efecto, en la medida que el asociante vaya registrando ingresos por el negocio en marcha, que califiquen como renta gravada, estos debieran considerarse para efecto del pago a cuenta; inclusive, aunque dichos importes no se hayan cobrado. Por su parte, el asociado, quien no tendría que tributar por la utilidad que le corresponda por el negocio, no debería efectuar pagos a cuenta por este concepto.

g) Por último, es de destacar que, de acuerdo con el artículo 18 de la Ley del IGV, solo otorgan derecho al crédito fiscal, entre otros, las prestaciones o utilizaciones de servicios que reúnan los siguientes requisitos:

- Sean permitidos como gasto o costo de la empresa, de acuerdo a la legislación del IR, aun cuando el contribuyente no esté afecto a este último impuesto.

- Se destinen a operaciones por las que se deba pagar el impuesto.

Ahora bien, pensemos en el ejemplo de los CAEP empleados para figuras como negocios inmobiliarios, en donde muchas veces es el asociado quien se encarga de realizar las compras y adquisiciones necesarias para la ejecución del proyecto, pagando el IGV correspondiente en dichas operaciones y acumulando un importante crédito fiscal.

Pues bien, si como resultado del negocio finalmente aquel asociado recibiría una renta desgravada, no tendrá derecho a aplicar como crédito fiscal el impuesto que grave sus operaciones afectas.

Cabe mencionar que, dicho impuesto podría ser aplicado como gasto del asociado, de conformidad con el artículo 69 de la Ley del IGV(18).

En suma, las cuestiones antes descritas son solo algunas de las interrogantes que hoy surgen en torno al tratamiento del CAEP. Evidentemente, la presencia de puntos críticos acompañados de vacíos normativos, van en claro detrimento de la seguridad jurídica de los administrados.

Mención aparte merece lo anterior, toda vez que, si bien en nuestro ordenamiento jurídico no hay una remisión expresa al concepto de seguridad jurídica ${ }^{(19)}$, el Tribunal Constitucional

(18) La citada norma indica lo siguiente:

"Artículo 69.- El crédito fiscal no es gasto ni costo

El Impuesto General a las Ventas no constituye gasto ni costo para efectos de la aplicación del Impuesto a la Renta, cuando se tenga derecho a aplicar como crédito fiscal". 
La problemática tributaria de los contratos de asociación en participación The tax problems of the Partnership agreement (Joint Venture)

se refiere a este como un pilar consubstancial del Estado Constitucional de Derecho, principio constitucional, relacionándolo con la predictibilidad de las conductas (en especial, la de los poderes públicos) frente a los supuestos previamente determinados por el Derecho, señalando que la seguridad jurídica "es la garantía que informa a todo el ordenamiento jurídico y que consolida la interdicción de la arbitrariedad" (Zuzunaga del Pino 2013, 59).

En efecto, a través de la Sentencia vinculada al Expediente $\mathrm{N}^{\circ} 16-2002-\mathrm{Al} / \mathrm{TC}^{(20)}$, el Tribunal Constitucional establece lo siguiente:

"La seguridad jurídica es un principio que transita todo el ordenamiento, incluyendo, desde luego, a la Norma Fundamental que lo preside. Su reconocimiento es implícito en nuestra Constitución, aunque se concretiza con meridiana claridad a través de distintas disposiciones constitucionales, algunas de orden general, como la contenida en el artículo $2^{\circ}$, inciso 24 , parágrafo a) ("Nadie está obligado a hacer lo que la ley no manda, ni impedido se hacer lo que ella no prohíbe"), y otras de alcances más específicos (...)".

Así, con cargo a realizar un análisis más minucioso, desde nuestro punto de vista es posible señalar que, en tanto no se esclarezcan los temas antes resaltados, se estaría siendo vulnerado el aludido principio en menoscabo de los contribuyentes.

En cualquier caso, estamos seguros de que la reciente jurisprudencia será óbice para la emisión de un próximo pronunciamiento con carácter de observancia obligatoria del Tribunal Fiscal; y, necesariamente, de alguna modificación legislativa, en donde esperamos se puedan esclarecer algunos de los supuestos en cuestión.

\section{Referencias bibliográficas}

Blanco, Andrés. 2013. El valor del "Comentario OCDE" en la solución de problemas jurídicos tributarios. Revista del Instituto Peruano de Derecho Tributario 53 (febrero): 5-22.

Castillo Botetano, Lourdes. 2012. Problemática en la aplicación del Impuesto a la Renta en las asociaciones en participación. Revista del Instituto Peruano de Derecho Tributario 52 (abril): 51-72.

García-Pita y Lastres, José Luis. 2008. El derecho de sociedades en el Perú: un análisis comparativo. Revista Ita Ius esto 1: 17-57.

Hundskopf, Oswaldo. 2005. La Asociación en Participación como contrato de riesgo compartido y no de prestaciones recíprocas. Diálogo con la Jurisprudencia 84 (setiembre): 143-6.

Medrano Cornejo, Humberto. 2000. Impuesto a la Renta y contratos de colaboración empresarial. Themis 41: 97-105

Navarro Palacios, Indira. 2002. Análisis tributario de los contratos de asociación en participación y de consorcio. Revista Peruana de Derecho de la Empresa 54: 90-117.

Talledo Mazú, César. La asociación en participación, el consorcio y el joint venture: aspectos contractuales y tributarios. Cuadernos Tributarios 22 Revista de la Asociación Fiscal internacional (IFA) Grupo Peruano (diciembre): 25-49.

Zuzunaga del Pino, Fernando. 2013. ¿La Cláusula Antielusiva General vulnera la Constitución Peruana? Revista del Instituto Peruano de Derecho Tributario 53 (febrero): 23-65.

(19) Así lo advierte correctamente el profesor Del Busto, al señalar que: "Nuestra Constitución reconoce explícitamente el derecho de toda persona a la seguridad personal y también a la seguridad social. No se refiere expresamente a la seguridad jurídica, aunque es claro que los dos reconocimientos antedichos son otras tantas especies de la seguridad jurídica". Jorge Del Busto Vargas, "El Principio de Seguridad Jurídica en la creación y aplicación del Tributo", Revista del Instituto Peruano de Derecho Tributario 29 (diciembre 1995): 75-94.

(20) De fecha 30 de abril de 2003. La misma cita es incluida en la Sentencia vinculada a los Expedientes $\mathrm{N}^{\circ} 1-2003-\mathrm{Al} / \mathrm{TC}, \mathrm{N}^{\circ}$ 2-2003-AI/TC y 3-2003-AI/TC. 